RESEARCH ARTICLE

\title{
Occlusion: What's behind a Bite? Study of the Knowledge and At- titude about Principles of Occlusion among Dental Professionals
}

\author{
Moksha Nayak and Drisya Soman* \\ Department of Conservative Dentistry \& Endodontics, KVG Dental College \& Hospital, India \\ *Corresponding author: Drisya Soman, Post Graduate Student, Department of Conservative Dentistry \\ \& Endodontics, KVG Dental College \& Hospital Sullia Dakshina Kannada, 574327, Karnataka, India, Tel: \\ 9480135090, E-mail: soman.drisya@gmail.com
}

\begin{abstract}
Aim: General dental practitioners and dental professionals can play an essential role in education and motivation of their patients about the principles and practice of of occlusion; which can be very beneficial to the patient's lifestyle. It is, therefore, important to identify their level of knowledge and attitude toward attaining proper occlusion. This study was aimed to analyse the knowledge and attitude about principles of occlusion in general dental practitioners and other specialists including post graduate students in dentistry.
\end{abstract}

Materials and methods: A cross sectional study was conducted on 418 dental professionals selected from various regions of Karnataka and Kerala. A questionnaire consisting of 16 questions was handed to the subjects willing to participate in the present study to assess their knowledge $\&$ attitude about the principles of occlusion. The subjects were grouped as general dental practitioners (Group 1), conservative dentists (Group 2), specialists (Group 3), and post graduates (Group 4). The scores were calculated, and statistical analysis was done with the help of IBM SPSS statistics 20, using Student's t test.

Results: The comparative analysis showed highly significant difference of knowledge and attitude score between general dental practitioners and non-orthodontic specialists (Student's $t$ test, $P<0.001)$. The total mean score was calculated for the study groups which was 11.9 for general practitioners, 17.58 for conservative dentist, 18.50 for other specialists and 9.20 for post graduates respectively. Speciality wise total mean score was also calculated which accounted for 19.03 for Orthodontists, 18.38 for Prosthodontists, 17.58 for Conservative dentists followed by other specialists.

Conclusion: The knowledge and awareness prevalent regarding occlusion among the study participants was moderately satisfactory. But the study results definitely highlight the need for more education of practice and treatment concepts in attaining proper occlusion to the dentists who did not belong to this field. The awareness regarding basic facts and recent treatment options is mandatory.

\section{Keywords}

Occlusion, Dental professionals, Questionnaire, Awareness

\section{Introduction}

Oral health generally has the effect on the general health of the individual and ultimately affects wellbeing, education, and development. One of the most common etiologies for the development of dental caries, fluorosis, temporomandibular disorders and gingival diseases is not attaining proper occlusion [1]. Tooth malposition may also lead to difficulty in functional movements of the mandible, difficulty in mastication, swallowing, speech, increased susceptibility to trauma or periodontal problems. Therefore, it becomes important to educate the individuals about the benefits of proper occlusion of teeth. This can be accomplished by a multidisciplinary approach in which general dental practitioners and other specialists can play role of oral health educators, but only if they have good knowledge and attitude about the principles of proper occlusion. The aim of the present study was to evaluate the knowledge and attitude about principles of occlusion among general dental practitioners (BDS), conservative dentists \& endodontists (MDS), other practicing specialists (MDS) and post graduate students (PGs).

\section{Materials and Methods}

A cross sectional study was conducted on dental professionals selected from various regions of Karnataka and Kerala. Total information about the study was given to all participants through personal contact,

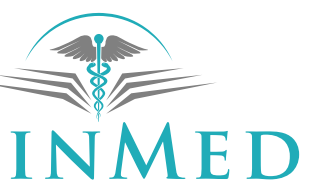

INTERNATIONAL LIBRARY

Citation: Nayak M, Soman D (2018) Occlusion: What's behind a Bite? Study of the Knowledge and Attitude about Principles of Occlusion among Dental Professionals. Int J Oral Dent Health 4:050. doi. org/10.23937/2469-5734/1510050

Received: February 16, 2018: Accepted: April 30, 2018: Published: May 02, 2018

Copyright: (C) 2018 Nayak M, et al. This is an open-access article distributed under the terms of the Creative Commons Attribution License, which permits unrestricted use, distribution, and reproduction in any medium, provided the original author and source are credited. 
phone as well as through email, and informed consent was obtained from each of the participants involved in the study. The study included practicing dentists with bachelor's degree in dental surgery, master's in dental surgery including post graduates while non-practicing dental professionals were excluded from the study. The subjects were grouped as general dental practitioners (Group 1), conservative dentists (Group 2), specialists (Group 3), and post graduates (Group 4).

A questionnaire consisting of 16 questions was handed to 600 subjects of which 418 subjects willing to participate in the present study to assess their knowledge $\&$ attitude about the principles of occlusion. The questions were of Yes/No type and each correct answer were given a Score 1 and incorrect answer was given Score zero (Appendix I).

\section{Statistical analysis of data}

Scores were calculated based on the responses given by participants. The individual scores were summed up to get the total score. Statistical analysis was performed with the help of IBM SPSS statistics 20, with the help of Student's t test.

\section{Results}

Among 418 participants, 60 were general dental practitioner, 190 specialists, 70 conservative dentists and 98 post graduates. Out of these, 235 (68.6\%) were males, and 183 were females (31.4\%) (Table 1 ).

The total mean score was calculated for the study groups which was 11.9 for general practitioners, 17.58 for conservative dentists, 18.50 for other specialists and 9.20 for post graduates respectively (Table 2). Speciality wise total mean score was also calculated which

Table 1: Gender-wise distribution between groups.

\begin{tabular}{|l|l|l|l|}
\hline Group & Males & Females & Total \\
\hline Group I: General practitioners (BDS) & 42 & 18 & 60 \\
\hline Group II: Conservative Dentists (MDS) & 43 & 27 & 70 \\
\hline Group III: Other Specialists (MDS) & 105 & 85 & 190 \\
\hline Group IV: Post graduates & 45 & 53 & 98 \\
\hline Total & 235 & 183 & 418 \\
\hline
\end{tabular}

Table 2: Total mean score between groups.

\begin{tabular}{|l|l|l|l|}
\hline Group & & N & $\begin{array}{l}\text { Total } \\
\text { score }\end{array}$ \\
\hline $\begin{array}{l}\text { General dental practitioners } \\
\text { (BDS) }\end{array}$ & Male & 42 & 10 \\
\cline { 2 - 3 } & Female & 18 & 9.82 \\
\hline & Total mean score & 60 & 11.9 \\
\hline $\begin{array}{l}\text { Conservative dentistry \& } \\
\text { endodontists (MDS) }\end{array}$ & Male & 43 & 17.6 \\
\hline & Female & 27 & 17.4 \\
\hline \multirow{3}{*}{ Other specialists (MDS) } & Total mean score & 70 & 17.58 \\
\hline Post graduates & Male & 105 & 16.28 \\
\hline & Female & 85 & 15.2 \\
\hline & Total mean score & 190 & 18.5 \\
\hline & Male & 45 & 9.01 \\
\hline & Female & 53 & 9.38 \\
\hline & Total mean score & 98 & 9.2 \\
\hline
\end{tabular}

accounted for 19.03 for Orthodontists, 18.38 for Prosthodontists, 17.58 for Conservative dentists followed by other specialists (Table 3).

Comparison of the total score of questions between general dental practitioner, and other specialties using Student's $\mathrm{t}$ test showed highly significant difference (Table 4, Student's $t$ test, $\mathrm{P}<0.001$ ). Comparison of the scores between specialists and Conservative dentists using Student's t test was also statistically significant. (Table 5, Student's t test, $\mathrm{P}<0.001$ )

\section{Discussion}

Occlusion is the commencing and the terminating position of all functional movements of stomatognathic system. It has a multifactorial functional relationship between the teeth and the masticatory system [2]. According to Shiv kumar, et al. in India the prevalence of malocclusion varies from $20 \%$ to $43 \%$ [3]. Evaluation of the location, direction, and area of tooth contacts during various mandibular movements is an essential part of the preoperative evaluation of teeth to be restored. Not respecting the dento-facial system may result in restoration, prosthesis, or periodontal treatment failures, along with relapse of orthodontic and orthognathic surgeries [4].

Comparison of the knowledge scores between general dental practitioners and specialties was done in the present study which showed highly significant differ-

Table 3: Speciality wise-total mean score.

\begin{tabular}{|l|l|l|}
\hline Group & N & Total score \\
\hline Conservative dentists & 70 & 17.58 \\
\hline Orthodontists & 45 & 19.03 \\
\hline Prosthodontists & 40 & 18.38 \\
\hline Pedodontists & 38 & 16.89 \\
\hline Periodontists & 33 & 16.24 \\
\hline Oral surgeons & 28 & 16.41 \\
\hline Public health dentists & 3 & 16.05 \\
\hline Oral medicine \& radiology & 3 & 16.81 \\
\hline Oral pathologist & 2 & 16.02 \\
\hline
\end{tabular}

Table 4: Comparison of the scores between general dental practitioners and other specialists.

\begin{tabular}{|l|l|l|l|l|}
\hline Group & $\mathbf{n}$ & $\begin{array}{l}\text { Scores } \\
\text { (Mean } \pm \text { SD) }\end{array}$ & t value & Significance \\
\hline $\begin{array}{l}\text { General dental } \\
\text { practitioners }\end{array}$ & 60 & $11.9 \pm 1.58$ & 5.619 & $\mathrm{P}<0.001^{* *}$ \\
\hline Specialists & 260 & $17.5 \pm 1.87$ & & \\
\hline *Difference was statistically significant; SD: Standard Deviation.
\end{tabular}

Table 5: Comparison of the scores between specialists and conservative dentists.

\begin{tabular}{|l|l|l|l|l|}
\hline Group & $\mathbf{n}$ & $\begin{array}{l}\text { Scores } \\
\text { (Mean } \pm \text { SD) }\end{array}$ & t value & Significance \\
\hline $\begin{array}{l}\text { Specialists } \\
\begin{array}{l}\text { Conservative } \\
\text { dentists }\end{array}\end{array}$ & 70 & $18.56 \pm 1.78$ & 2.4509 & $\mathrm{P}<0.001^{* *}$ \\
\hline
\end{tabular}

*Difference was statistically significant; SD: Standard Deviation. 
ence between the groups $(77.4 \%$ in general dental practitioners and $88.5 \%$ in specialists). This was justified by the study conducted by Sastri, et al. ( $80.4 \%$ for general dentists $87.5 \%$ for specialists) [5]. It indicates that the knowledge of the specialties in dentistry, which is given three more years of their life for the education in specialty of dentistry, was more as compared to the general dental practitioners.

Total mean scores of general practitioners were more compared to post graduates showing that experience in practice gives better awareness.

Total score of knowledge and attitude compared between male and female participants showed male predilection as compared to females. Niveda, et al. reported a total mean score of $15.35 \pm 2.37$ for male practitioners and $14.60 \pm 1.96$ for females [6]. This showed that male practitioners had more positive knowledge and attitude than female dental practitioners, toward principles and practice of proper occlusion.

Specialty wise total mean score revealed that Orthodontists and prosthodontists has a better awareness on occlusion than other specialists including conservative dentists. This may be due to that fact that University Syllabus has special emphasis on thorough knowledge of occlusion from basics to advanced with specific marks entitled to it for these two specialities (Orthodontics \& prosthodontics) which is lacking in other specialities.

\section{Conclusion}

This particular comparative study added more focus on the facts of existing condition and scenario of the knowledge and attitude of the general dental practitioners and other practicing specialties of dentistry toward the principles and practice of maintaining proper occlusion. Therefore, the study showed the need for increased clinically oriented education of practice and concepts of achieving proper occlusion. The knowledge and awareness prevalent among the study participants was moderately satisfactory. But the study results definitely highlight the need for more education of practice and treatment concepts in orthodontics to the dentists who did not belong to this field. The awareness regarding such basic facts and recent treatment options is mandatory. Therefore, continuing dental education programs are the need of the hour to constantly update the recent advances among the general dentists. It would be also definitely beneficial if the curriculum in the dental colleges and universities can be modified and upgraded to include the modern concepts and therapeutic options. The undergraduates and post graduate students should be trained right from the student days and can be exposed to multidisciplinary recent updates. We plan to conduct the study on a larger population in the fourth coming days to have a more precise evaluation of the existing scenario.

\section{References}

1. Haralur SB, Addas MK, Othman HI, Shah FK, El-Malki Al, et al. (2014) Prevalence of malocclusion, its association with occlusal interferences and temporomandibular disorders among the Saudi sub-population. Oral Health Dent Manag 13: 164-169.

2. Pandey M, Singh J, Mangal G, Yadav P (2014) Evaluation of awareness regarding orthodontic procedures among a group of preadolescents in a crosssectional study. J Int Soc Prev Community Dent 4: 44-47.

3. Lew KK (1993) Attitudes and perceptions of adults towards orthodontic treatment in an Asian community. Community Dent Oral Epidemiol 21: 31-35.

4. Roberson, Theodore M, Harald Heymann, Edward J Swift, Clifford M (2006) Clinical significance of Dental Anatomy, Histology, Physiology and Occlusion. In: Sturdevant's Art and Science of Operative Dentistry. St. Louis, 60.

5. Shenoy R (2012) Occlusion: The gateway to success. J Interdiscip Dentistry 2: 228.

6. Niveda S, Saravana D (2014) A survey of the knowledge, attitude and awareness of principles and practices in orthodontics among general dentists and nonorthodontic specialists. IOSR J Dent Med Sci 13: 44-46.

7. Ray HA, Trope M (1995) Periapical status of endodontically treated teeth in relation to the technical quality of the root filling and the coronal restoration. Int E Journal 28: 12-18. 


\section{Appendix I}

Questionnaire

\section{Category}

$\begin{array}{lll}\text { a) General practitioner } & \text { b) specialist } & \text { c) endodontist }\end{array}$

2. Do you consider that well-aligned teeth are important for overall facial appearance?
a) Yes
b) No

3. Do you always look for malocclusions on clinical examination when patients report with any other complaint?
a) Yes
b) No

4. When do you check the occlusion in your daily practice?
a) before treatment
b) after treatment
c) before and after treatment
5. Which type of occlusion do you check?
a) molar
b) canine
c) both

6. Do you know that temporomandibular joint disorders can be cured by orthodontic therapy?
a) Yes
b) No

7. Do you convince the patient for the orthodontic treatment?
a) Yes
b) No

8. Do you call specialist (orthodontist) for an opinion?
a) Yes
b) No

9. Do you carry out diagnostic orthodontic procedures?
a) Yes
b) $\mathrm{No}$

10. Is orthodontic treatment recommended for patients having periodontal problems?
a) Yes
b) No

11. Do you deny orthodontic treatment for patients with missing molar?
a) Yes
b) No

12. Are you aware that few teeth may have to be removed for aligning irregular teeth?
a) Yes
b) No

13. Does occlusion has any significant role in restorative dentistry?
a) Yes
b) No

14. Does malocclusion cause caries?
a) Yes
b) No

15. Can traumatic occlusion play a role in the initiation and progression of pulp and periradicular inflammation
a) Yes
b) No

16. Do you believe that straightening the teeth makes better smile, helps in mastication, better oral hygiene, easier to speak, healthy lifestyle?
a) Yes
b) No 